\title{
Constructive-technological diagram of the rotary-string cultivator and the definition of its main parameters
}

\author{
Vladimir Konovalov ${ }^{1, *}$, Sergey Konovalov ${ }^{1}$, and Victoria Igumnova ${ }^{1}$ \\ ${ }^{1}$ Kuban State Agrarian University named after I.T.Trubilin, 350044, Krasnodar, Russia
}

\begin{abstract}
Organizing technological processes in accordance with adopted system of agriculture, producers of agricultural products tend to get maximum possible yield with minimizing costs and increasing the level of soil fertility. A fallow system is one of effective systems of soil processing for accumulation of nutrients and moisture, as well as weed control. Fallow cultivation of soil is used when using this system for weed control. First cultivation is carried out with help of fallow or continuous cultivators, which have low productivity and high energy intensity. To eliminate these shortcomings, authors proposed a structural and technological scheme of a rotor-lug cultivator, the main element of which is rotor-string working bodies on flexible shaft. Tillage rotary-string work by hauling leads to propelling-rotational effects. There were obtained analytical dependences for determining speed of string required for cutting stem of weeds under different physical-mechanical parameters of stem and soil, as well as technological indicators of a cultivator' operation. The authors obtained expressions for determining the radius of string installation from axis of rotation, angle of section installation to the direction of motion of energy means, as well as the number of strings required for guaranteed cutting of weeds deeper than the point of growth.
\end{abstract}

\section{Relevance of research}

Any agricultural enterprise at growing of cultivated plants organizes all technological processes according to system of agriculture accepted in it. The main purpose of any farming system is to increase maximum crop yield with minimum given costs $[3,9]$. The system of agriculture includes a number of organizational and economic, agrotechnical, reclamation, soil protection measures. All activities should form effective use of soil, agroclimatic resources, maximum biological potential of plants, as well as lead to increase in soil fertility.

In the system of agriculture, a special place is given to system of soil cultivation, which includes various technologies and agricultural techniques, depending on physical and

\footnotetext{
* Corresponding author: konovalov.v.i@mail.ru
} 
mechanical properties of soil, agro-climatic conditions, as well as pre-existing and subsequent culture [6].

Of the various systems of soil content, one of the most effective soil structuring is a fallow system in terms of accumulation of nutrients and moisture, as well as weed control. Under fallowed field we understand the field, on what a certain amount of time cultivated plants are not grown but periodically soil treatment is carried out in order to combat weeds [7]. In conditions of Krasnodar Territory, as a rule, a system used is called busy fallow, and processing soil in this case is called semi-fallow. With such a system of soil management, early harvested crops, such as winter wheat, are sown into field, and after their harvesting, it is recommended to conduct stubble dehulling by disk working bodies in order to embed residual moisture and seeds of weeds and drops. Then soil ploughing is carried out with introduction of main dose of mineral and entire dose of organic fertilizers, as well as all improvers, if necessary. Further soil management is in its cultivation in order to combat weeds.

Fallow cultivation is carried out for loosening and leveling the top layer of soil, cutting roots of weed vegetation. Cultivation is carried out using fallow or blind cultivators. Significant disadvantages of fallow cultivators include high energy consumption, poor copying of soil topography and low productivity of the process. With increase in speed of movement of a cultivator over $10-12 \mathrm{~km} / \mathrm{h}$, spread of soil increases sharply, which negatively affects clogging of working bodies and its erosion danger.

\section{Target setting}

Of the various types of cultivators we can identify rod or cable designed for fallow and pretillage. Rod cultivators are no longer used due to a number of shortcomings, which include poor penetration, uneven depth of treatment, ability to work only on loose soils, low speed, up to $10 \mathrm{~km} / \mathrm{h}$, as well as a relatively complex design of the rod drive. However, they had a number of advantages. The main advantage of a rod cultivator is a very high degree of stubble preservation up to $90 \%$, i.e. no removal of wet soil layers to surface, which contributes to accumulation and preservation of moisture in it. In this case, weeds are torn by a rod, pulled out and scattered on surface.

\section{Analysis of achievements and publications}

Development of new tillage technologies is necessarily associated with use of new technical means and approaches that combine the already achieved technological processes with addition of new concepts [4]. It is possible to increase efficiency of fallow and presowing tillage by using rotary-string working bodies on flexible shaft. The design and technological scheme of rotor-string cultivator proposed by us includes a central bar of frame on which support wheels are installed to maintain the depth of processing, hinged device and sections of working bodies [5]. Section (Fig. 1) consists of working body 1, it is frame 2 with lugs 3 . The framings are connected with each other by means of link 4 , and there are strings 5 between lugs. The working body is attached on both sides to bearing units 6 , which in turn are mounted on movable frame 7 and fixed frame 8 . Lanyard 9 is between fixed 7 and movable 8 frames, which allows you to move the movable frame relative to the fixed one, thereby changing the tension force of flexible shaft of the working body. The moving frame 7 through brackets is attached to the larger 11 and smaller 12 brackets of frame, which are installed directly on beam of frame of a harrow with help of clinches 13 . 


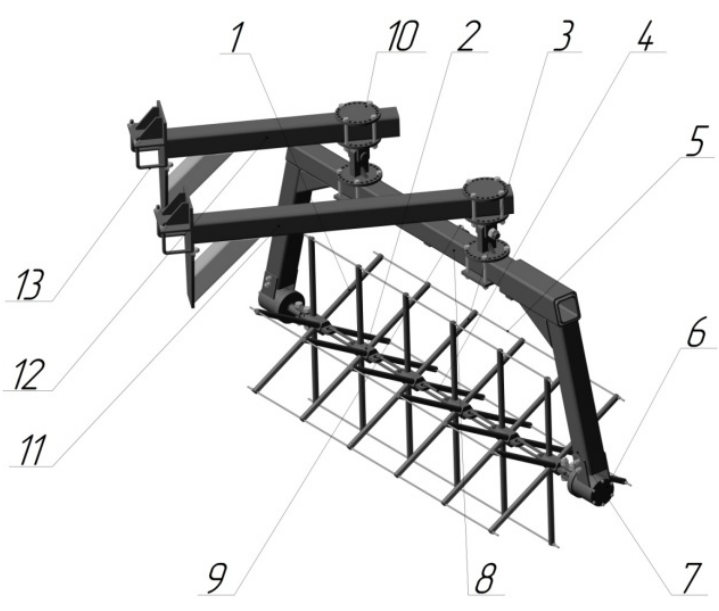

Fig. 1. Design and technological scheme of section of rotor-string cultivator: 1 - working body; 2 framing; 3 - lug; 4 - link; 5 - string; 6 - bearing unit; 7 - mobile frame; 8 - fixed frame; 9 - lanyard; 10 - blacket; 11 - large blacket of frame; 12 - small blacket of frame; 13 - clinch.

The proposed design and technological scheme of a rotor-string working body at work is hooked by its lugs with soil, while their deepening, rotation along axis of flexible shaft, also loosening and leveling of soil. Simultaneously with lugs, strings will be deepened, which in process of their rotation will produce undercutting of root system, its combing and cleaning from weeds. The location of a working body on flexible shaft will maintain depth of processing and copy soil surface with high accuracy. The joint movement of a working body and a cultivator will lead to a pulling-rotational effect on soil, leading to a better leveling of soil surface, and a flexible shaft will avoid damage to a working body when they reach critical loads. In addition, the proposed design and technological scheme allows to increase speed of a unit to $15-20 \mathrm{~km} / \mathrm{h}$ and to increase a width of gripping up to 1.5-2 times, which significantly increase productivity and reduce energy intensity of process.

\section{Presentation of main material of research}

When designing a rotor-lug cultivator for maximum possible efficiency of its work, first of all, setting of its design and technological parameters are carried out, which include: radius of working body, number of strings, width of grip and angle of its installation to direction of motion.

Weeds can be cut by static or dynamic forces. Static action of force is not applicable to working processes of agricultural machines. When cutting stem by dynamically acting force additionally due to bending of stem there are forces of stem's inertia. In addition, since a stem is cut in soil, there is also a force of soil resistance to crumpling, which prevents bending [1]. All these forces create resistance that allows you to cut a stem (Fig. 2 ). In this case, the condition of cutting a stem by a string will be follows:

$$
P_{\text {cut }}<P_{\text {bend }}+P_{\text {in }}+P_{\text {soil }},
$$

where $P_{\text {cut }}$ - force of cutting stem by string;

$P_{\text {bend }}$ - resistance of stem to bending;

$P_{\text {in }}$ - force of stem's inertia:

$P_{\text {soil }}$ - resistance of soil crumpling; 


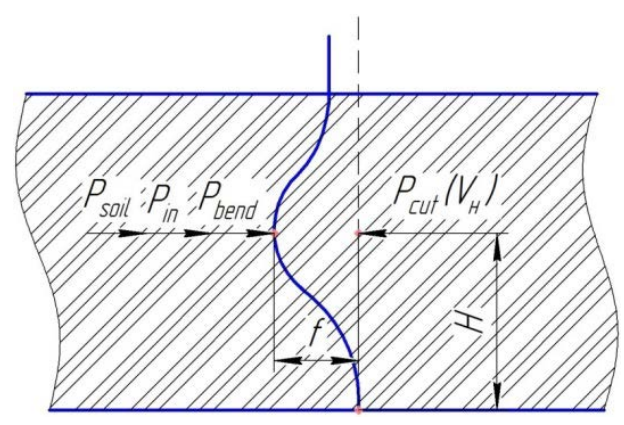

Fig. 2. Scheme of interaction of string to stem.

When considering the process of cutting stem with a string, it can be considered as a cantilevered rail rigidly fixed by root system in the base and loaded with force of $R_{\text {cut }}$, seeking to cut it at speed at height $H$ from a fixing point. If time of interaction of a string with stem is designated as $\Delta t$, then during this period of time stem is deflected from original position by value of $f$. In this case, there is a bending resistance in stem, which will be determined by the expression [1]:

$$
P_{b e n d}=\frac{3 f E J}{H^{3}}
$$

where $f$ - value of deviation of stem from vertical position;

Specific soil resistance to crumpling can be expressed by coefficient of volumetric crumpling, which is determined by the expression [8]:

$$
g=\frac{P}{V}
$$

where $g$ - coefficient of volumetric soil crumpling, $\mathrm{H} / \mathrm{cm}^{3}$, for ploughed field $g=1-2 \mathrm{H} / \mathrm{cm}^{3}$, for stubble and fallow $g=5-10 \mathrm{H} / \mathrm{cm}^{3}$;

$V$ - volume of crumpled soil, $\mathrm{cm}^{3}$.

Axial section of stem is a cone, and cylinder should be taken to simplify the problem with sufficient accuracy (Fig. 3) [10]. In this case, volume of crumpled soil will be the product of area segment to height of stem section subjected to indentation into soil and depend on value of a central angle or a length of a tightened chord.

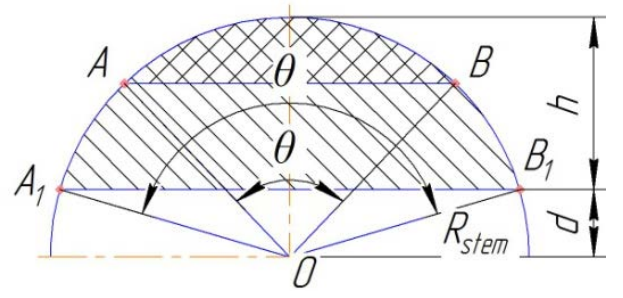

Fig. 3. Scheme of crumpled soil volume.

Area of segment is determined by the expression [2]:

$$
S=\frac{1}{2} R_{\text {stem }}^{2}(\theta-\sin \theta),
$$

where $S$ - square of segment;

$R_{\text {stem }}$ - radius of stem in point of cutting; 
$\theta$ - angle of bail's segment in radians.

The angle of bail's segment is determined from the expression:

$$
\theta=2 \arccos \left(\frac{R_{\text {stem }}-h}{R_{\text {stem }}}\right),
$$

where $h$ - height of segment.

Substituting expressions (4) and (3) into expression (2), performing transformations, we obtain:

$$
P_{\text {soil }}=\frac{1}{2} g l R_{\text {stem }}^{2}\left[2 \arccos \left(\frac{R_{\text {stem }}-h}{R_{\text {stem }}}\right)-\sin \left(2 \arccos \left(\frac{R_{\text {stem }}-h}{R_{\text {stem }}}\right)\right)\right],
$$

where $l$ - height of area of stem subjected to indentation into soil.

Since the magnitude of stem deviations from a vertical position will depend on speed of $\mathrm{v}_{\text {str }}$ of string, and time of contact with stem $f=v_{0} \Delta t$ and average acceleration of stem $j=$ $\left(v_{s t r}-v_{0}\right) / \Delta t$, where initial velocity of stem is $v_{0}=0$, condition of stem cutting will be:

$$
P_{\text {cut }}<\frac{3 f E J}{H^{3}}+\frac{m v_{\text {str }}}{\Delta t}+\frac{1}{2} g l R_{\text {stem }}^{2}\left[2 \arccos \left(\frac{R_{\text {stem }}-h}{R_{\text {stem }}}\right)-\sin \left(2 \arccos \left(\frac{R_{\text {stem }}-h}{R_{\text {stem }}}\right)\right)\right],
$$

Expressing velocity of string $v_{\text {str }}$ from the expression (6) we obtain:

$$
v_{\text {str }}>\frac{2 P_{\text {cut }} H^{3} \Delta t-\frac{1}{2} H^{3} \Delta t g l R_{\text {stem }}^{2}\left[2 \arccos \left(\frac{R_{\text {stem }}-h}{R_{\text {stem }}}\right)-\sin \left(2 \arccos \left(\frac{R_{\text {stem }}-h}{R_{\text {stem }}}\right)\right)\right]}{6 \Delta t^{2} E J+2 m H^{3}}
$$

The expression (7) shows dependence of velocity of string necessary for cutting a stem due to physical and mechanical properties of stem and soil, as well as technological indicators of a cultivator. Since a rotor-string working body acts on soil with a pullingrotation movement, velocity of string depends on a cultivator's velocity itself and magnitude of coefficients of adhesion and slippage of lugs with soil and movers of energy means. If we assume that angular velocity of a drive wheel or a sprocket of engine is equal to angular velocity of rotor-lug working body with permissible amount of slippage, velocity will be determined:

$$
v_{s t r}=\frac{R_{s t r} v_{\text {mover }} \mu_{\text {mover }} \mu_{s t r}\left(1-\delta_{\text {mover }}\right)\left(1-\delta_{s t r}\right)}{R_{\text {mover }}},
$$

where $R_{s t r}$ - radius of string setting from axis of rotation;

$v_{\text {mover }}$ - velocity of movement of energy means;

$\mu_{\text {mover }}, \mu_{\text {str }}$ - coefficient of adhesion with soil corresponding to a mover of energy means and lugs of working body;

$\delta_{\text {mover }}, \delta_{\text {str }}$ - coefficient of slippage corresponding to a mover of energy means and working body;

$R_{\text {mover }}$ - radius of leading wheel and sprockets of a mover of energy means.

Then expressing the radius of installation of string from axis of rotation $R_{\text {str }}$ from the expression (7) we obtain:

$$
R_{s t r}=\frac{v_{s t r} R_{\text {mover }}}{v_{\text {mover }} \mu_{\text {mover }} \mu_{s t r}\left(1-\delta_{\text {mover }}\right)\left(1-\delta_{s t r}\right)}
$$


The expression (9) shows the dependence of value of radius of string installation on axis of rotation necessary to give it the required velocity $v_{s t r}$ for cutting stem from parameters of a propulsive agent, adhesion and slippage. The value of the adhesion and slippage of working bodies can only be determined empirically at different degrees of tension of axis of flexible shaft.

According to the obtained expressions, it is possible to determine velocity of string and radius of its installation relative to axis of rotation in the case when axis of rotation is perpendicular to the direction of motion of energy means. In case of location of a section of a rotor-lug cultivator at an angle to direction of motion of energy means, velocity of string, as can be seen from triangle of velocities reduces, and will be determined by the expression:

$$
v_{\text {str }}=v_{\text {mover }} \cos \alpha,
$$

where $\alpha$-angle of setting of section relatively to direction of energy means movement.

In this case, when installing the section of rotor-lug cultivator at an angle to the direction of motion of energy means, in the expression (9) it is necessary to substitute the value of a string velocity after its recalculation by the expression (10).

The angle of installation of section of a rotor-lug cultivator affects quality of weed cutting, so it is necessary to ensure its pinching between string and soil to cut a stem. In this case, the installation angle will be $[11,12]$ :

$$
\alpha \leq \varphi_{1}+\varphi_{2}
$$

where $\varphi_{1}$ - angle of stem's friction on string;

$\varphi_{2}-$ angle of stem's friction on soil;

To determine the minimum number of strings on working body, we will proceed from the fact that when turning the flexible shaft, at least one string is guaranteed to cut the weed vegetation along the entire width of the grip. Scientists recommend a cutting of weed vegetation below the point of growth, which is usually at depth of $2-3 \mathrm{~cm}$ from surface of field. This condition will be met if, when the flexible shaft is rotated, at least two strings are in soil. Then under conditions of uniform arrangement of strings the angle $\beta$ formed between adjacent strings. In this case, when flexible shaft is rotated, depth of string stroke will be crumpled from minimum to maximum value and vice versa, and value of this angle $\beta$ between adjacent strings is determined by the expression:

$$
\beta=2 \arcsin \left(\frac{\sqrt{R_{s t r}^{2}-\left(R_{s t r}-h_{d e p}+h_{c u t}\right)}}{R_{s t r}}\right),
$$

where $\beta$ - angle between adjacent strings;

$h_{\text {dep }}$ - maximum depth of string;

$h_{\text {cut }}$ - depth of weed cutting.

In this case, provided a uniform arrangement of strings on working body, their number is determined:

$$
n=\frac{2 \pi}{\beta}
$$

where $n$ - number of strings on working body.

The resulting value of expression (13) must be rounded to a larger integer, which will ensure cutting of weeds deeper than the point of growth. 


\section{Conclusions}

The proposed constructive and technological scheme of a rotor-lug working body will increase the productivity of fallow tillage during the storage of processing depth, guaranteed cutting of weed vegetation and without removal of wet soil layers to surface. The obtained analytical dependences make it possible to determine main constructive and technological parameters of rotor-lug working body depending on physical and mechanical properties of soil and stems of weeds, as well as parameters of propelling agent of energy means.

\section{References}

1. E. S. Bosoy, I. I.Smirnov, O. V. Vernyaev, E. G. Sultan-shakh, Theory, construction and calculation of agricultural machines (Moscow, "Mechanical engineering”, 1978)

2. M. Ya. Vygodsky, Guide to Higher Mathematics (Moscow: AST: Astrel, 2006)

3. Yu. K. Kastidi, D. A. Krepyshev, Economic efficiency of Krasnodar Territory commodity producers supply with agricultural machinery, Proceedings of Kuban State Agrarian University, v. 28. pp. 39-42 (2011)

4. G. Maslov, A. S. Serganov, Innovative technology in energy-saving technologies of field crops, Proceedings of Kuban State Agrarian University, v. 71, pp. 110-117 (2018)

5. V. I. Konovalov, S. I. Konovalov, O. V. Konovalova, E. S. Movchan, Flexible rotating harrows, Patent 173221 of the RF, MPK A01V 21/00, applicant and patent holder. Federal State Budgetary Educational Institution "Kuban State Agrarian University named after I.T.Trubilin», № 2017125814, order 18.07.2017, published 26.03.2018, Bul, v. 9, pp. 5

6. P. N. Rybalkin P. N. [et al.], New adaptive energy-and soil-saving technologies of winter wheat and maize cultivation in Krasnodar Territory, (Krasnodar: Russian Academy of Agricultural Sciences, Krasnodar Research Institute of Agriculture. P. P. Lukyanenko, 2002)

7. P. N. Rybalkin P. N. [et al.], Agronomic requirements for main technological operations with adaptive technologies of winter cereals and maize cultivation and new technical means for their implementation in Krasnodar Territory, (Krasnodar: Department of agriculture and food of Krasnodar Territory, Russian Academy of Agricultural Sciences, Krasnodar Research Institute of Agriculture. P. P. Lukyanenko, 2001)

8. V.A. Romanenko [et al.], Agricultural machines (device, operation and basic adjustments), (Krasnodar, KubSAU, 2014)

9. A. P. Sokolova, Yu. K. Kastidi, G. F. Bershitskaya, M. E. Trubilin, Impact of machinery supply on economic performance of crop production, Rural mechanic, v. 2, pp. 22-23 (2015)

10. K. A. Sokht, E. I. Trubilin, V. I. Konovalov, Statistical methods of researches of processes and machines in agribusiness (Krasnodar: KubSAU, 2016)

11. E. I. Trubilin, K. A. Sokht, V. I. Konovalov, Improving the technological reliability of disk harrows and ploughs, Equipment and machinery for rural areas, v. 6, pp. 12-15 (2013) 
12. E. I. Trubilin, V. I. Konovalov, S. I. Konovalov, Theoretical study of ways to improve efficiency of disk tillage tools, Proceedings of the Kuban State Agrarian University, v. 65, pp. 165-171 (2017) 